\title{
Combined 33rd SICOT and 17th PAOA Orthopaedic World Conference
}

\author{
Maurice Hinsenkamp
}

Received: 29 June 2012 / Accepted: 4 July 2012 / Published online: 31 July 2012

(C) Springer-Verlag 2012

Since 2006, the continual year-on-year growth of the SICOT annual meetings has made it harder to differentiate between the Annual World Conferences and the Triennial World Congresses as the annual conferences have become so strongly supported. This constant expansion has been in part reflected by the larger number of abstracts submitted but also in the representation from an ever increasing number of countries, with especially strong growth from continents such as Asia who have greatly increased their participation.

During the three days of the conference, from November 28 to 30 , four plenary speakers will present their outstanding expertise in ACL reconstruction (Freddie H FU), lower limb deformities (Gawal Ahmed Hosny), ten-year results with highly cross-linked polyethylene (Chitranyan Ranawat) and osteochondral talar defect (Niek van Dijk)

Thirty symposia offer a synthesis of the state of the art on current hot topics in orthopaedic surgery from the fundamental aspects to clinical practice. The emphasis will be placed on some specific topics such as the management of delayed and neglected fracture, the fracture around the ankle prepared by our Trauma Committee and sickle cell osteonecrosis of the hip. This panel of symposia is completed by the participation of Specialty Societies including ASAMI, ARTOF, IFPOS, IGASS and WOC. Our French colleagues, during the SOFCOT Symposium, will also give their experiences on the reverse shoulder prosthesis.

Sixty-eight free paper sessions will cover large fields of interest in traumatology and orthopaedic surgery. Every

M. Hinsenkamp $(\bowtie)$

Department of Orthopaedic Surgery,

Hôpital Erasme-Université Libre de Bruxelles,

Route de Lennik,

808, 1070 Brussels, Belgium

e-mail: mhinsenk@ulb.ac.be subspecialty is represented during the full three days of the meeting. They will be completed by 1,024 e-poster presentations. As with last year, focus poster sessions will be concentrated around selected topics allowing theme-oriented discussion.

To satisfy the quest for knowledge and learning of your young colleagues, 11 instructional courses organised by world specialists will cover a great variety of topics including hip preservation surgery for young adults, osteotomy around the knee, subtalar arthroscopic procedures, anterior shoulder instability, failed back surgery, fractures of the distal tibia and ankle and polytrauma management.

Our Editor of International Orthopaedics, Marko Pecina, is organising a symposium on how to write a paper/how to read a paper critically and what the reviewer is looking for. This will help both young and senior colleagues to improve the quality of the papers submitted to International Orthopaedics. Our journal maintains and even improves its high standard allowing every orthopaedic surgeon in the world to publish in International Orthopaedics and to be read by an international forum of experts. In 2011, the impact factor of International Orthpaedics is 2.025.

In Dubai, we will continue to explore specific aspects of natural disaster medical assistance, less known by civilian orthopaedic surgeons. In addition to an ICL, a symposium will be organised on triage to improve the preparation of volunteering SICOT members for this kind of mission organised in collaboration with MSF. At the 2011 SICOT meeting in Prague there was a symposium on amputation after man made or natural disaster. The main presentations have been published in International Orthopaedics [1-6]. Application to be recruited into the SICOT volunteers team is now open with some additional information on the SICOT website (www.sicot.org).

SICOT is also part of the notification programme of WHO which aims to raise the concern of orthopaedic 
surgeons regarding the ethical and vigilance aspects of the use of allografts [7]. The strict regulation applied in some countries should be generalised and the information on how to use substances of human origin circulated to the world. A representative of WHO will introduce a symposium devoted to massive reconstruction by allograft. References to this WHO programme are also available on the SICOT website where a notification form of adverse effects can also be found (www.sicot.org).

Our local Conference President, Hashem Al Khatib, has worked very hard to host you in the most exceptional venue of Dubai. The Dubai Meydan night will be a wonderful souvenir of this meeting. We hope to see you in Dubai to share your experience and knowledge with your colleagues from all over the world in a welcoming and fraternal atmosphere.

Maurice Hinsenkamp

SICOT President

\section{References}

1. Hinsenkamp M (2012) SICOT contribution to natural disasters assistance. Int Orthop 36. doi:10.1007/s00264-012-1554-1

2. Herard P (2012) Amputation in emergency situations: indications, techniques and MSF-France's experience in Haiti. Int Orthop 36. doi:10.1007/s00264-012-1552-3

3. Wolfson N (2012) Amputation in natural disasters and mass casualties: staged approach. Int Orthop 36. doi:10.1007/s00264-0121573-y

4. Rigal S (2012) Extremity amputation: how to face challenging problems in a precarious environment. Int Orthop 36. doi:10.1007/ s00264-012-1548-z

5. Awais SM (2012) Amputations of limbs during the 2005 earthquake in Pakistan: a first hand experience of the author. Int Orthop 36

6. Demey D (2012) Post-amputation rehabilitation in emergency crisis from pre-operative to community. Int Orthop 36

7. Hinsenkamp M, Muylle L, Eastlund T, Fehily D, Noël L, Strong DM (2012) Adverse reactions and events related to musculoskeletal allografts: reviewed by the World Health Organisation Project NOTIFY. Int Orthop 36(3):633-641 